Received: 19 July 2018

Accepted: 28 February 2019

Published online: 26 March 2019

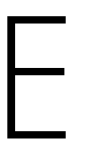

C

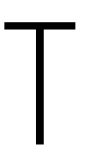

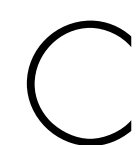

REP

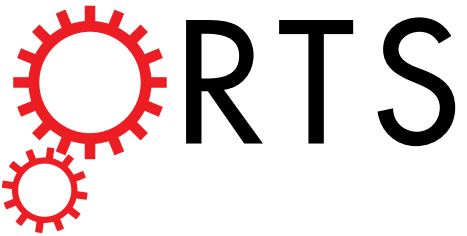

\title{
OPEN
}

\section{Development of model web-server for crop variety identification using throughput SNP genotyping data}

Rajender Singh ${ }^{1}$, M. A. Iquebal ${ }^{2}$, C. N. Mishra ${ }^{1}$, Sarika Jaiswal ${ }^{2}$, Deepender Kumar ${ }^{1}$, Nishu Raghav ${ }^{1}$, Surinder Paul ${ }^{1}$, Sonia Sheoran ${ }^{1}$, Pradeep Sharma ${ }^{1}{ }^{1}$, Arun Gupta ${ }^{1}$, Vinod Tiwari ${ }^{1}$, U. B. Angadi ${ }^{2}$, Neeraj Kumar' ${ }^{2}$, Anil Rai ${ }^{2}$, G. P. Singh ${ }^{1}$, Dinesh Kumar ${ }^{2}$ \& Ratan Tiwari ${ }^{1}$

Crop varieties or genotypes of a given species are pivotal for agricultural production and ownership, management and improvement of their germplasm is a great challenge. Its morphological identification requires time, cost and descriptors are often compromised statistically due to phenotypic plasticity. Development of DNA based signature of varieties can overcome these limitations. There is a global need to implement world trade organization (WTO) and intellectual property rights (IPR) guidelines of Plant Breeders Rights (PBR) where DUS (distinctness, uniformity and stability) testing can be supplemented by DNA profile. Universalization and minimization of SNP number without compromising identification accuracy is the major challenge in development of varietal profile by rapid genotype assay. Besides this, there is no server-based approach reducing computational skill with global accessibility of referral phenotypic and genotypic data. We report world's first model web server for crop variety identification using $>350$ Indian wheat varieties and Axiom $35 \mathrm{~K}$ SNP chip data. Standard filtering and linkage disequilibrium approach were used to develop varietal signature in Linux using HTML, Java, PHP and MySOL with provision of QR code generator to facilitate bar-coding. Phylogenetic tree constructed by selected SNPs confirms six major trait based clusters of varieties and their pedigree. Our user friendly server based tool, VISTa (Variety Identification System of Triticum aestivum) (http://webtom.cabgrid. res.in/vista) can be used in DUS testing having dispute resolution of sovereignty and access benefit sharing (ABS) issues. This model approach can be used in other crops with pan-global level management of crop germplasm in endeavour of crop productivity.

Out of 250-300 thousands edible plant species, only 5\% are relevant to agriculture. Among these, three species, namely maize, rice and wheat fulfills $60 \%$ of the caloric needs of humans ${ }^{1}$. Crop variety resources are pivotal for agricultural production, their selection and management is an integral part of variety development ${ }^{2}$. The identification of large number of plant varieties solely on the basis of morphological characters is difficult due to growth stage specificity and phenotypic plasticity ${ }^{3}$. Development of DNA based signature profiles of released varieties to compare with candidate variety or future variety is required.

In sweep of globalization having WTO and IPR guidelines, it is imperative to have rapid and highly reliable method of plant variety identification system (VIS). Traditional approaches of VIS were exclusively dependent on morphological characters (descriptors) having compromised precision and time consuming. For example, in potato varieties having 50 characters, 12 of them are time dependent with growth stage, which can never be rapid. Such limitations are encountered in almost every crop ${ }^{3}$. To protect intellectual property (IP) of variety by granting statutory Plant Breeders Rights (PBR), it requires testing of distinctness, uniformity and stability (DUS) called DUS testing. It has limitations like growth stage specificity, environmental influence, phenotypic plasticity, ineffectiveness over large collections, lack of rapidity besides statistical compromise in the values of descriptors. If VIS tool is available to breeders, growers and the general industry, it would be instrumental in rapid identification, germplasm registration and traceability of the produce of concerned crop variety. Such tool can also prevent

${ }^{1}$ ICAR-Indian Institute of Wheat \& Barley Research, Karnal, 132001, Haryana, India. ${ }^{2}$ CCAR- Indian Agricultural Statistics Research Institute, New Delhi, 110012, India. Rajender Singh and M. A. Iquebal contributed equally. Correspondence and requests for materials should be addressed to Dinesh K. (email: dinesh.kumar@icar.gov.in) or R.T. (email: Ratan.Tiwari@icar.gov.in) 
economic loss of variety developer's investment, which may happen due to deceptive indication of variety status by unauthorized user of variety. The majority of the crop diversity is present in developing countries and global use of germplasm is often encountered with sovereignty and access benefit sharing (ABS) issues ${ }^{4}$.

This is a great challenge for taxonomy, law, ethical consideration and technology to establish varietal status. For example, wheat varietal disputes over varieties Nap-Hal and Galahad having quality trait for biscuits, flour and dough making are globally best known example ${ }^{5}$ where Patent EP 445929 was revoked. Molecular markers especially protein profiling of glutenin and gliadins to supplement DUS features are reported more than a decade ago, where centralized publically accessible data on referral varieties can be used as "last resort" to resolve the dispute $^{6}$.

Use of next generation sequence based approaches has emerged as a powerful tool for characterization of varieties based on genomic sequence differences. Single Nucleotide Polymorphisms (SNPs) are the most common type of genomic variations which represent differences in a single DNA building block. Therefore, SNP markers relate to their ease of data management along with their flexibility, speed and cost effectiveness. In fact $>50$ SNP arrays are available for $>25$ various crop genomes ${ }^{7}$. There is no dearth of molecular data for variety identification but VIS still has the challenge of universalization of SNPs across variety, SNP minimization, development of genotype assay, multiplexing, computational skill, online accessibility of molecular data along with variety descriptor. Pan-global approach of development of VIS is still lacking.

Till now there is no web-based methodology/ approach for varietal identification of any crop using throughput SNP data. There is a need to develop a user friendly server based tool where no computational skill is required and user can obtain variety identification results with its DUS features. Such tool can further supplement DUS varietal testing, which would be more relevant in era of globalization where transboundary movement of germplasm often leads to sovereignty disputes. We report world's first model web server of any crop for variety identification using Indian wheat varieties and its Axiom $35 \mathrm{~K}$ SNP data as an example.

\section{Materials and Methods}

DUS Phenotyping of model crop wheat. Extensive phenotyping was done to generate data of wheat DUS features to confirm the varietal status of a panel of 368 Indian spring wheat genotypes to be used in the study. The panel constituted were represented by 116 released varieties, 45 registered genetic stocks, 117 advanced breeding lines and 90 Indian landraces. Among 36 DUS features 28 were qualitative or categorical and 8 were quantitative. The DUS features represents 8 plant description traits, 9 ear characters, 6 flag leaf attributes, 6 glume features, 4 grain appearance and 3 grain quality traits. The characters were recorded according to DUS test guidelines framed by Protection of Plant Varieties and Farmers' Rights Authority, India (http://plantauthority. gov.in/pdf/GBread\%20Wheat.pdf). The quantitative characteristic, except days to heading and test weight, were recorded from ten plants in each of three replications. The days to heading was recorded on plot basis while thousand grains were randomly selected and weighed for test weight. The qualitative characters were recorded by the visual assessment on individual plant or on parts of the plants of individual genotypes. Out of 27 traits of latest 2017 UPOV guidelines 24 traits are covered in our recording barring three, namely, (i) straw: pith in cross section, (ii) Apical rachis segment: area of haireness on convex surface and (iii) lower glume: area of hairiness on internal surface.

DNA extraction and SNP genotyping. DNA was isolated from the leaves of two week old seedlings using CTAB method ${ }^{8,9}$. The DNA samples were genotyped using Axiom ${ }^{\circledR}$ Wheat Breeder's Genotyping Array (Affymetrix UK Ltd, UK).

SNP data analysis. Filtering of SNPs was done with parameters: call rate $(<95 \%)$, monomorphic, $>10 \%$ missing value, MAF $(<0.05)$ and heterozygosity $(>1 \%)$. Remaining SNPs were used for further analysis. Statistical values, namely, minor allele frequency (MAF), gene diversity, heterozygosity and Polymorphic Information Content (PIC) for each SNP were estimated using PowerMarker v3.25 $5^{10}$. In development of any crop variety identification methodology/system, the smallest number of markers discriminating all or maximum number of varieties in the panel are most desirable. Such approach of SNP minimization reduces the cost of genotyping without compromising the identification accuracy ${ }^{11,12}$. In fact 2-3 SNP/per chromosome are enough for variety identification ${ }^{13}$. In order to minimize number of SNPs, pairwise locus Linkage Disequilibrium (LD) was estimated by TASSEL 3.0 ${ }^{14}$. Further SNPs were selected based on following criteria: (1) SNP markers with PIC value more than 0.35 , (2) the SNP marker were selected based on the consensus map derived from five mapping populations (Allen et al., 2016) where each SNP was mapped in at least in two mapping populations (http://www. cerealsdb.uk.net/cerealgenomics/CerealsDB/axiom_download.php), (3) atleast two markers from each chromosome were selected for distinguishing genotypes and to differentiate closely related genotypes, more SNP markers were included (4) SNP markers were selected in such a way that they are not closely linked to each other except two markers each on chromosomes 2A, 6A and 7B. Graphical representation of the distribution of SNP markers on 21 chromosomes was done using GGT software $2.0^{15}$. The position of SNP markers in terms of genetic distance (cM) were based on consensus genetic map generated from five mapping populations ${ }^{14}$. With the objective of not compromising the utility value of the SNP panel in resolving differences between close genotypes, markers differentiating those genotypes were also included. The genetic distances across the genotypes and neighbor-joining (NJ) tree based on Nei 1983 were calculated using PowerMarker v3.25 and NJ trees visualized using MEGA $4^{16}$. BA codes were retrieved from CerealsDB (http://www.cerealsdb.uk.net/cerealgenomics/CerealsDB/indexNEW. php) which corresponds to Affymetrix Axiom array SNP markers (http://www.cerealsdb.uk.net/cerealgenomics/ CerealsDB/axiom_download.php). Further these BA codes were used to search EnsemblPlants T. aestivum database (http://plants.ensembl.org/) to find the position of variants. 


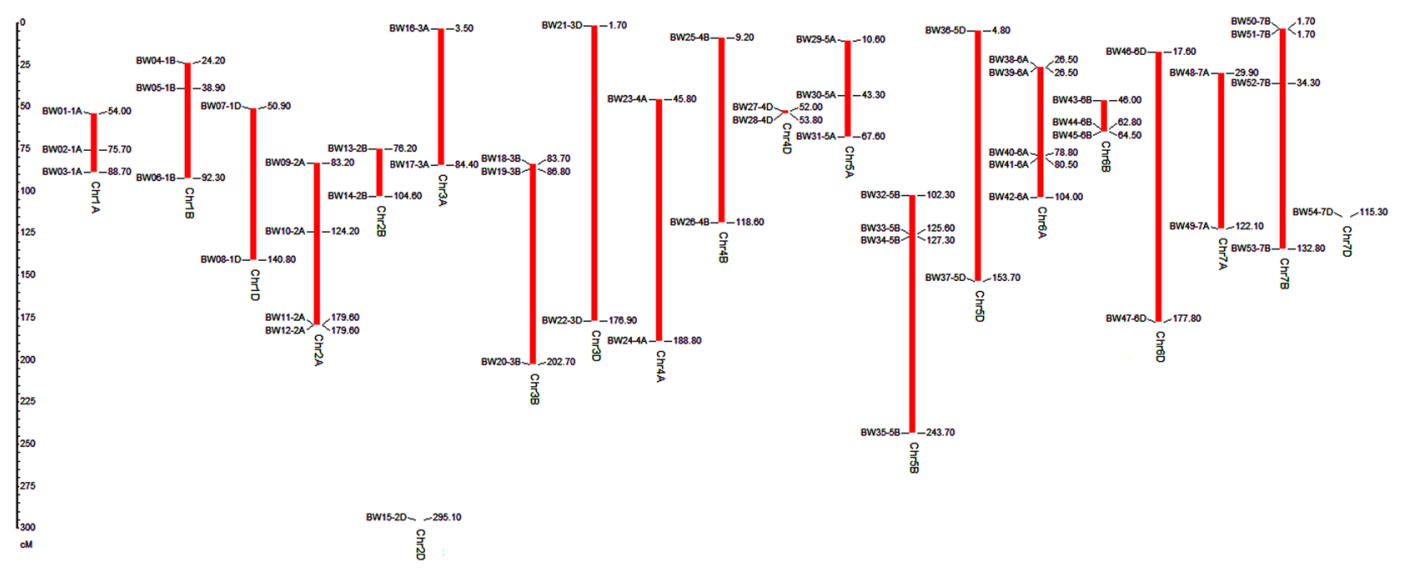

Figure 1. Relative position based on the framework markers position of $54 \mathrm{SNP}$ across the 21 chromosomes. Ruler on the left side denotes centiMorgan (cM) distance and horizontal lines across the chromosomes indicate locus positions on each chromosome.

Putative candidate gene analysis. To find the putative candidate genes for the reported SNPs, we performed a BLASTn search of NCBI database (http://www.ncbi.nlm.nih.gov/) with the SNP sequences. The putative candidate genes identified from BLASTn were further searched in UniProtKB (https://www.uniprot.org/) to find the putative biological functions which were supported by existing literature. In case of hypothetical proteins, they were characterized by predicting its genes and translated proteins using protein BLAST (PAM algorithm having lenient stringency).

Generation of 2-D barcode. For accessions being used in this study, 2D barcode was generated using online tool (available at www.barcode-generator.org). Each accession and its genotype based SNP barcode was used as input to generate corresponding $2 \mathrm{D}$ barcode. Once the barcode was generated, it was scanned for the confirmation of information used for creating the $2 \mathrm{D}$ barcode.

Development of web-based variety identification system for wheat. Variety Identification System for Triticum aestivum (VISTa) was developed in a LINUX operating system using HTML and JAVA as client-side scripting, PHP as server side scripting language and MYSQL as the RDBMS to store genotype data of 368 wheat verities with 54 SNPs markers. This is launched on Apache internet server. VISTa tool has provision to enter query data, search and measure the distance of query data against database along with the presentation of results in tabular and graphical mode. This web-based tool is easy to use and allows access to varietal identification and validation along with database through a user-friendly web- browser. The database is designed and developed on relational database concept. VISTa is intended to store and manage genotype data of 368 varieties of wheat and fast data retrieval required through web-interfaces. HTML and java scripting languages have been used for client side operations such as manual data entry, loading data from a text file and QR code image file. The sample data is kept in the server for users for ease of understanding and its implementation. PHP server-side language has been used for database connectivity, retrieval of data and calculation of distance measure of query data against database. HTML and Java scripting language has been used for illustration of results in tabular and graphical form. For most convenient remote location use, a mobile app has also been developed. We opted for QR code for information matrix due to its advantages, namely, being two-dimensional, it can hold more information (both horizontally and vertically), and thus minimizing space needed for printing in leveling of wheat seeds/produce. This will have more convenience and ease in labeling of germplasm especially while managing in wet-lab and crop-field both. Such approach has advantage of error-free, machine based retrieval of information and effective transmission required in germplasm management. It can be read in 360 degrees thus more convenient. It can also accommodate symbol/logo etc. of variety holder/ organization, if required.

\section{Results and Discussion}

Minimization of SNPs for crop variety DNA signature development. Of 35143 SNPs obtained with Axiom ${ }^{\circledR}$ Wheat Breeder's Array, 6041 SNPs were removed having a call rate $<95 \%$ leaving 29102 SNPs for downstream analysis. Out of these, 3.54\% (1031) SNPs were monomorphic and $1.54 \%$ (448) showed $>10 \%$ missing values. These SNPs were removed from the dataset. In addition, 7680 (26.39\%) SNPs with a MAF of $<0.05$ and 3878 (13.33\%) SNPs with >1\% heterozygosity were also excluded from the dataset. Remaining 16065 (55.2\%) SNPs were included for further analysis. The genotypes included in the study were released varieties, registered genetic stocks, advanced breeding lines and landraces. The MAF of SNPs ranged from 0.05 to 0.5 with average 0.2619 . The gene diversity across 16065 loci ranged from 0.095 to 0.5 with average 0.3537 . The mean PIC value of SNPs was 0.2837 with a range of 0.0905 to 0.375 .

Of the total 16065 SNPs, we identified 54 SNP markers which singled out each of the 368 genotypes used in present study. These markers were distributed throughout the wheat genome (Fig. 1). Each chromosome had two or more markers except chromosome 2D and 7D having one SNP marker. Chromosome 6A had highest five markers. The MAF of the SNP ranged from 0.0976 to 0.5 with average MAF 0.4271 . The gene diversity across 


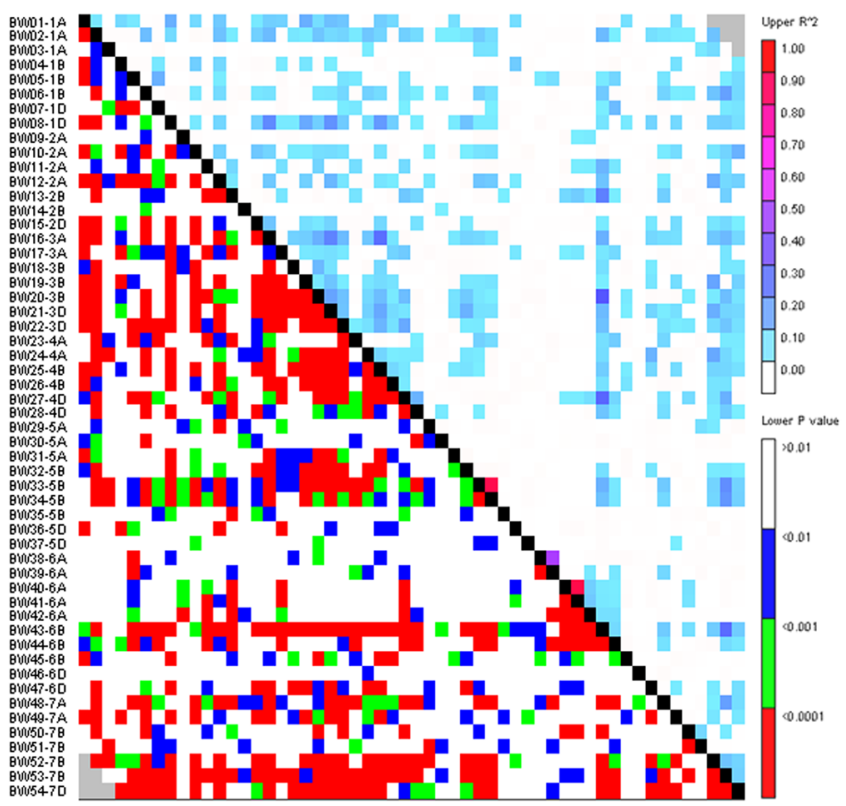

Figure 2. Heat map of linkage disequilibrium $(\mathrm{LD})$ value $\left(\mathrm{R}^{2}\right)$ across the wheat 21 chromosomes measured with 54 SNPs. Markers were ordered on the $x$ and $y$ axes based on genomic location so that each cell of the heat map represents a single marker pair. The $\mathrm{R}^{2}$ values for each marker pair are on the bottom half of the heat map and are represented by shades of colour from 0.0 (white) increasing in darkness in equal increments of 0.1 to 1.0 (red). The $\mathrm{p}$-values of each $\mathrm{R}^{2}$ estimate are on the top half of the heat map and are represented by shades of colors from non-significant ( $\mathrm{p}>0.01$; white) highly significant $(\mathrm{p}<0.0001$; red).

54 loci ranged from 0.1761 to 0.5 with average 0.4764 . All the SNP markers were having PIC value of $>0.3$ with average PIC value 0.3615, except two markers on chromosome 5D, namely, AX-95632832 (PIC 0.1606) and AX-94534026 (PIC 0.2506). All the 54 SNP loci were highly informative as they behave independently having loose $\mathrm{LD}$ among them (mean $R^{2}=0.03$ ) except a pair of markers on chromosome 5B and 6A (Fig. 2). LD can be computed to exclude large number of SNPs (minimization of SNP number). Such approach can select SNPs from each haploblock which are segregating independently. Similar approach has been successfully used in wheat ${ }^{17,18}$ and Plasmodium ${ }^{19}$.

Present finding of SNP based differentiation of 368 wheat genotypes confirms the earlier reports that SNP markers have ability to estimate diversity and relatedness in various crops ${ }^{7}$. Genetic resources available in gene banks need detailed characterization so as to enable breeders to utilize them more efficiently. Pure lines or inbreds in crops often contain a multitude of genetically very similar cultivars that require use of highly robust SNP markers for such discrimination. SNP arrays have been efficiently used in several species for discriminating individuals, understanding relatedness across genomes such as Plasmodium falciparum ${ }^{19}$, Mycobacterium tuberculosis ${ }^{20}$ and crops ${ }^{17,21-23}$. In earlier report, a set of 43 SNPs were unable to differentiate $15.2 \%$ of the wheat cultivars because of close relationships among the Chinese accessions ${ }^{17}$. Moreover, these sets of SNP loci are more informative having mean $\mathrm{R}^{2}=0.03$, in comparison to the earlier report $\mathrm{t}^{17}$.

Our findings of differentiation of 368 Indian wheat varieties by 54 SNP markers are well in terms of number of varieties and markers in tune of other reports. For example, differentiation of 429 wheat varieties differentiation by $43 \mathrm{SNP}^{17}, 537$ varieties of potato by $50 \mathrm{SNPs}^{24}, 137$ soybean varieties differentiation by $20 \mathrm{SNPs}^{25}, 121$ hop crop varieties differentiation by $7 \mathrm{SNPs}^{12}$, grape variety differentiation by $2-3 \mathrm{SNP} /$ per chromosome ${ }^{13}$, cotton varieties differentiation by 23 core SNP markers ${ }^{26}$ and maize variety differentiation by UPOV using 16 SNP markers ${ }^{27}$. The SNPs identified in our study can be converted into user friendly genotyping assay like KASP/ CASP.

Phylogenetic tree construction. Phylogenetic tree constructed using 54 SNPs were found in conformity with their pedigree. There were six clusters representing pre-dominant group of varieties having some common traits or origin or pedigree. They represent predominantly short duration early maturing varieties (cluster 1), predominantly rainfed varieties (cluster 2), predominantly indigenous Indian collection and Mexican cultivars that paved the way for green revolution (cluster 3), predominantly genetic stocks for disease (brown/ black/yellow rusts, leaf blight) resistance (cluster 4), predominantly multi-parent derived recent genotypes having PASTOR and MILAN in their pedigree (cluster 5) and predominantly derivatives of PBW343 ('Veery' line) (cluster 6) (Fig. 3, Table 1). It further confirms the efficacy and validity of tree constructed, endorsing validity of our approach.

In the present study, 54 SNP markers were effective enough to differentiate 368 spring genotypes of bread wheat. These markers were able to distinguish the cultivars derived from common lineage such as DPW621-50, DBW88 and HD3059; HD3016, WH1132, WH1138. A summary of genotypes falling in various groups along with the predominant progenitor is mentioned in Table 2. 


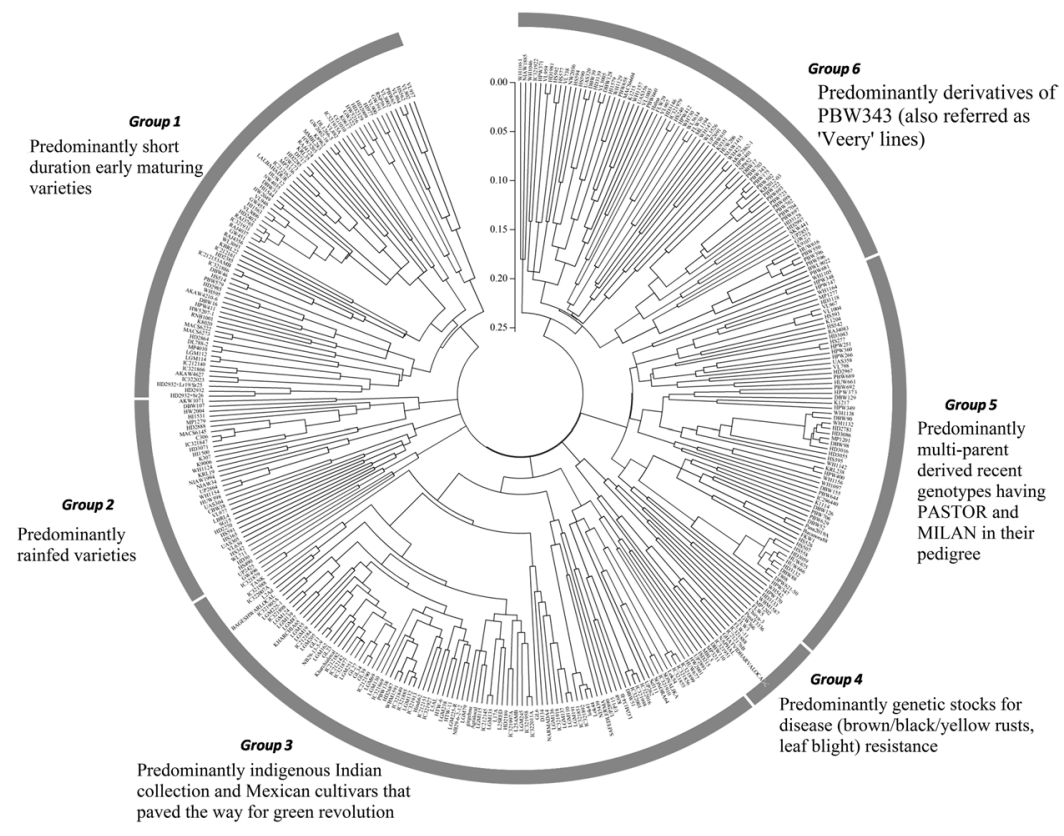

Figure 3. Phylogenetic analysis of 368 wheat genotypes based on the breeder's $35 \mathrm{~K}$ genotyping array. A neighbor-joining (NJ) tree was constructed using identified 54 SNP markers.

Putative role of genes having varietal signature SNP allele. Wheat Breeders' Array ( $35 \mathrm{~K})$ designed from $820 \mathrm{~K}$ array representing highly informative SNPs have direct implications for wheat breeders especially interested in comparing hexaploid germplasm ${ }^{28}$. SNPs identified in our study having high PIC value distributed on all the 21 wheat chromosomes were also found to possess putative functionality for different biological functions. Out of 54 SNPs, 10 were from non-coding region, thus we obtained putative function of remaining 44 SNPs of the coding regions. Functions of these genes were related to various traits such as flowering, cold acclimatization, water logging, photosynthesis and carbohydrate metabolism, drought/salt/aluminium stress tolerance, seed dormancy and disease resistance. These SNPs were from genes that encodes serine-threonine protein kinases, thiamine pyrophosphokinase 2, alpha-tubulins, methyl-binding domain proteins (MBD), MOTHER OF FT AND TFL1 (MFT), ETERNAL TAPETUM 1 (EAT1), sn-glycerol-3-phosphate acyltransferase, phosphoserine aminotransferase, enolase, glucan endo-1,3-beta-glucosidase, receptor protein kinase TMK1, NAC transcription factor, aluminum-activated malate transporter 1 (ALMT1) and ABC transporters (Supplementary Table 1) proteins which are involved in important biological processes.

Development of model web-based variety identification system. We report here the first model of crop variety identification system using SNP array using Triticum aestivum data in form of VISTa (http://webtom. cabgrid.res.in/vista/) tool which is based on minimum 54 SNPs and 36 DUS features differentiating $>350$ varieties. Data/ query can be uploaded and submitted in.txt or excel format or as QR code image in.jpeg format using PC, tablet or mobile device. This tool searches in all the 368 varieties across all the 54 SNPs to find the related varieties with similarity frequencies of each. User can also compare these varieties with 36 DUS features as well as 54 SNPs by checking the box. These tools can be of greater relevance for wheat breeders for in silico and rapid identification of varieties based on DUS features and SNPs. The full information of the related varieties can be viewed by putting the cursor on the graphical view.

SNP barcode provides a tool to discriminate very closely related accessions, traceability of minor crops in food supply chain, commercial frauds and dangerous substitution $\mathrm{s}^{29}$. Barcode of the selected 368 genotypes have been developed. Figure 4 depicts barcode of representative variety of wheat used in the present study. In some cases such varietal differentiation has been reported to increase the price tag value of wheat in the extent $>2$-folds in domestic and international market. For instance, Sharbati group of Indian wheat varieties like C306, HI 1500, HI 1531, HI 1544, MP 3211 etc fetch better return to farmers due to higher demand/ premium tag of the variety due to softness and taste of flat bread (chapati).

The developed model server, VISTa using varietal genomic data of wheat can be implemented in various other crops. While selecting SNP for varietal signature development, few other points must be considered. All SNP sets are not assayable due to genomic complexity and sequence dependent multiplexing parameters ${ }^{30}$. For example, in case of wheat, KASP assay development only $80 \%$ of SNP were assayable ${ }^{31}$. SNP present in intergenic or intronic region should be avoided as it might be casually associated, rather than causally. Similarly, silent mutation should be avoided as it is devoid of SAAP (single amino acid polymorphism). Preference should be given to SNPs present in coding region as they exhibit greater stability due to slow mutation rate and more likely to affect changes in the protein associated with phenotypic difference among varieties ${ }^{32}$. DUS feature associated SNP should be preferred ${ }^{33}$. Functional SNP selection offers the advantage due to their potential effect on plant 


\begin{tabular}{|c|c|c|c|c|c|c|c|}
\hline Marker & \begin{tabular}{|l} 
Assigned \\
code
\end{tabular} & Chromosome* & \begin{tabular}{|l|}
$\begin{array}{l}\text { Consensus } \\
\text { position }(\mathrm{cM}) *\end{array}$ \\
\end{tabular} & MAF & \begin{tabular}{|l} 
Gene \\
Diversity
\end{tabular} & PIC & Allele \\
\hline AX-94614591 & BW01-1A & $1 \mathrm{~A}$ & 54.04 & 0.4743 & 0.4987 & 0.3743 & $\mathrm{~T} / \mathrm{G}$ \\
\hline AX-94548062 & BW02-1A & $1 \mathrm{~A}$ & 75.74 & 0.4058 & 0.4823 & 0.3660 & $\mathrm{~T} / \mathrm{C}$ \\
\hline AX-94491525 & BW03-1A & $1 \mathrm{~A}$ & 88.71 & 0.3983 & 0.4793 & 0.3644 & $\mathrm{~A} / \mathrm{G}$ \\
\hline AX-94888336 & BW04-1B & 1B & 24.22 & 0.4738 & 0.4986 & 0.3743 & $\mathrm{~A} / \mathrm{G}$ \\
\hline AX-94755340 & BW05-1B & $1 \mathrm{~B}$ & 38.86 & 0.4753 & 0.4988 & 0.3744 & $\mathrm{~A} / \mathrm{G}$ \\
\hline AX-94986554 & BW06-1B & 1B & 92.32 & 0.4932 & 0.4999 & 0.3750 & $\mathrm{~A} / \mathrm{C}$ \\
\hline AX-94803245 & BW07-1D & $1 \mathrm{D}$ & 50.88 & 0.3856 & 0.4738 & 0.3616 & $\mathrm{~T} / \mathrm{C}$ \\
\hline AX-95070278 & BW08-1D & $1 \mathrm{D}$ & 140.84 & 0.4082 & 0.4832 & 0.3664 & $\mathrm{~A} / \mathrm{G}$ \\
\hline AX-94476558 & BW09-2A & $2 \mathrm{~A}$ & 83.23 & 0.3945 & 0.4777 & 0.3636 & $\mathrm{~A} / \mathrm{G}$ \\
\hline AX-94496990 & BW10-2A & $2 \mathrm{~A}$ & 124.18 & 0.3631 & 0.4625 & 0.3556 & $\mathrm{~T} / \mathrm{C}$ \\
\hline AX-95217784 & BW11-2A & $2 \mathrm{~A}$ & 179.61 & 0.4835 & 0.4995 & 0.3747 & $\mathrm{~A} / \mathrm{G}$ \\
\hline AX-94694991 & BW12-2A & $2 \mathrm{~A}$ & 179.61 & 0.4033 & 0.4813 & 0.3655 & $\mathrm{~T} / \mathrm{C}$ \\
\hline AX-94441179 & BW13-2B & $2 \mathrm{~B}$ & 76.24 & 0.4632 & 0.4973 & 0.3736 & $\mathrm{~T} / \mathrm{C}$ \\
\hline AX-95628947 & BW14-2B & $2 \mathrm{~B}$ & 104.59 & 0.3721 & 0.4673 & 0.3581 & $\mathrm{~A} / \mathrm{G}$ \\
\hline AX-94589168 & BW15-2D & $2 \mathrm{D}$ & 295.13 & 0.3179 & 0.4337 & 0.3397 & $\mathrm{~T} / \mathrm{C}$ \\
\hline AX-95023272 & BW16-3A & $3 \mathrm{~A}$ & 3.45 & 0.4959 & 0.5000 & 0.3750 & $\mathrm{~A} / \mathrm{G}$ \\
\hline AX-94664169 & BW17-3A & $3 \mathrm{~A}$ & 84.43 & 0.4973 & 0.5000 & 0.3750 & $\mathrm{~A} / \mathrm{G}$ \\
\hline AX-94693058 & BW18-3B & $3 \mathrm{~B}$ & 83.69 & 0.3817 & 0.4720 & 0.3606 & $\mathrm{~A} / \mathrm{C}$ \\
\hline AX-94975644 & BW19-3B & $3 \mathrm{~B}$ & 86.82 & 0.4109 & 0.4841 & 0.3669 & $\mathrm{~A} / \mathrm{G}$ \\
\hline AX-94704465 & BW20-3B & $3 \mathrm{~B}$ & 202.68 & 0.4675 & 0.4979 & 0.3739 & $\mathrm{~T} / \mathrm{C}$ \\
\hline AX-94609368 & BW21-3D & $3 \mathrm{D}$ & 1.69 & 0.4914 & 0.4999 & 0.3749 & $\mathrm{~A} / \mathrm{G}$ \\
\hline AX-94681475 & BW22-3D & $3 \mathrm{D}$ & 176.91 & 0.3736 & 0.4681 & 0.3585 & $\mathrm{~A} / \mathrm{C}$ \\
\hline AX-94795024 & BW23-4A & $4 \mathrm{~A}$ & 45.84 & 0.4563 & 0.4962 & 0.3731 & $\mathrm{C} / \mathrm{G}$ \\
\hline AX-95020717 & BW24-4A & $4 \mathrm{~A}$ & 188.85 & 0.4538 & 0.4957 & 0.3729 & $T / G$ \\
\hline AX-94575968 & BW25-4B & $4 \mathrm{~B}$ & 9.19 & 0.4659 & 0.4977 & 0.3738 & $\mathrm{~T} / \mathrm{C}$ \\
\hline AX-94522843 & BW26-4B & $4 \mathrm{~B}$ & 118.61 & 0.4000 & 0.4800 & 0.3648 & $\mathrm{~T} / \mathrm{C}$ \\
\hline AX-94971372 & BW27-4D & $4 \mathrm{D}$ & 51.97 & 0.4823 & 0.4994 & 0.3747 & $\mathrm{~T} / \mathrm{C}$ \\
\hline AX-94728173 & BW28-4D & $4 \mathrm{D}$ & 53.82 & 0.3424 & 0.4503 & 0.3489 & $\mathrm{~T} / \mathrm{G}$ \\
\hline AX-94438106 & BW29-5A & $5 \mathrm{~A}$ & 10.64 & 0.4819 & 0.4993 & 0.3747 & $\mathrm{~A} / \mathrm{T}$ \\
\hline AX-94686942 & BW30-5A & $5 \mathrm{~A}$ & 43.27 & 0.3590 & 0.4602 & 0.3543 & $\mathrm{~A} / \mathrm{G}$ \\
\hline AX-95630073 & BW31-5A & $5 \mathrm{~A}$ & 67.62 & 0.4918 & 0.4999 & 0.3749 & $\mathrm{~A} / \mathrm{G}$ \\
\hline AX-94816812 & BW32-5B & 5B & 102.31 & 0.2557 & 0.3806 & 0.3082 & $\mathrm{~T} / \mathrm{C}$ \\
\hline AX-94847013 & BW33-5B & $5 \mathrm{~B}$ & 125.63 & 0.4850 & 0.4996 & 0.3748 & $\mathrm{~A} / \mathrm{G}$ \\
\hline AX-95241690 & BW34-5B & $5 \mathrm{~B}$ & 127.3 & 0.4913 & 0.4998 & 0.3749 & $\mathrm{~T} / \mathrm{C}$ \\
\hline AX-94727602 & BW35-5B & $5 \mathrm{~B}$ & 243.74 & 0.5000 & 0.5000 & 0.3750 & $\mathrm{C} / \mathrm{G}$ \\
\hline AX-94534026 & BW36-5D & $5 \mathrm{D}$ & 4.8 & 0.1789 & 0.2937 & 0.2506 & $\mathrm{~T} / \mathrm{C}$ \\
\hline AX-95632832 & BW37-5D & $5 \mathrm{D}$ & 153.73 & 0.0976 & \begin{tabular}{|l|}
0.1761 \\
\end{tabular} & 0.1606 & $\mathrm{~A} / \mathrm{C}$ \\
\hline AX-94507146 & BW38-6A & $6 \mathrm{~A}$ & 26.51 & 0.4076 & 0.4829 & 0.3663 & $T / G$ \\
\hline AX-95230097 & BW39-6A & $6 \mathrm{~A}$ & 26.51 & 0.4849 & 0.4995 & 0.3748 & $\mathrm{~A} / \mathrm{G}$ \\
\hline AX-95229606 & BW40-6A & $6 \mathrm{~A}$ & 78.85 & 0.4709 & 0.4983 & 0.3742 & $\mathrm{~A} / \mathrm{C}$ \\
\hline AX-94437335 & BW41-6A & $6 \mathrm{~A}$ & 80.46 & 0.4850 & 0.4996 & 0.3748 & $\mathrm{~A} / \mathrm{G}$ \\
\hline AX-94551315 & BW42-6A & $6 \mathrm{~A}$ & 103.98 & 0.4206 & 0.4874 & 0.3686 & $\mathrm{~T} / \mathrm{C}$ \\
\hline AX-94699925 & BW43-6B & $6 \mathrm{~B}$ & 45.96 & 0.3071 & 0.4256 & 0.3350 & $\mathrm{~T} / \mathrm{C}$ \\
\hline AX-94986476 & BW44-6B & $6 \mathrm{~B}$ & 62.83 & 0.4959 & 0.5000 & 0.3750 & $\mathrm{~A} / \mathrm{G}$ \\
\hline AX-95160166 & BW45-6B & $6 \mathrm{~B}$ & 64.51 & 0.4860 & 0.4996 & 0.3748 & $\mathrm{~T} / \mathrm{G}$ \\
\hline AX-95130119 & BW46-6D & $6 \mathrm{D}$ & 17.65 & 0.4573 & 0.4964 & 0.3732 & $\mathrm{C} / \mathrm{G}$ \\
\hline AX-94388518 & BW47-6D & $6 \mathrm{D}$ & 177.76 & 0.4971 & 0.5000 & 0.3750 & $T / G$ \\
\hline AX-94417618 & BW48-7A & $7 \mathrm{~A}$ & \begin{tabular}{|l|}
29.9 \\
\end{tabular} & 0.4973 & 0.5000 & 0.3750 & $\mathrm{~A} / \mathrm{C}$ \\
\hline AX-95080011 & BW49-7A & $7 \mathrm{~A}$ & 122.12 & 0.4390 & 0.4926 & 0.3713 & $\mathrm{~A} / \mathrm{T}$ \\
\hline AX-94848356 & BW50-7B & $7 \mathrm{~B}$ & 1.72 & 0.4986 & 0.5000 & 0.3750 & $\mathrm{C} / \mathrm{G}$ \\
\hline AX-95121721 & BW51-7B & $7 \mathrm{~B}$ & 1.72 & 0.4802 & 0.4992 & 0.3746 & $T / G$ \\
\hline AX-95004702 & BW52-7B & $7 \mathrm{~B}$ & 34.33 & 0.4571 & 0.4963 & 0.3731 & $\mathrm{~A} / \mathrm{G}$ \\
\hline AX-94431804 & BW53-7B & $7 \mathrm{~B}$ & 132.83 & 0.4114 & 0.4843 & 0.3670 & $\mathrm{~T} / \mathrm{C}$ \\
\hline AX-94861586 & BW54-7D & $7 \mathrm{D}$ & 115.25 & 0.3945 & 0.4777 & 0.3636 & $\mathrm{C} / \mathrm{G}$ \\
\hline Mean & & & & 0.4271 & 0.4764 & 0.3615 & \\
\hline
\end{tabular}

Table 1. List of SNP markers used for distinguishing 368 wheat genotypes along with minor allele frequencies (MAF), PIC and genetic diversity ${ }^{*}$ Chromosomal position as per consensus map available on CerealsDB (http:// www.cerealsdb.uk.net/cerealgenomics/CerealsDB/indexNEW.php) 


\begin{tabular}{|c|c|c|c|}
\hline SN & Groups of genotypes & Genotypes & $\begin{array}{l}\text { Predominant progenitor/ } \\
\text { comments }\end{array}$ \\
\hline \multirow{3}{*}{1} & \multirow{3}{*}{ Predominantly short duration early maturing varieties } & K8962, HD2285, Raj3765, DBW 16, MP3336 & HD2160 \\
\hline & & GW322, MP3336, GW173 & GW173 \\
\hline & & VL802, VL804, HS562 & PBW65 \\
\hline \multirow{2}{*}{2} & \multirow{2}{*}{ Predominantly rainfed varieties } & HD2888, HW2004, MACS6145 & C 306 \\
\hline & & HI1531, HS365, K9006, K307 & BLUEBIRD \\
\hline \multirow[b]{2}{*}{3} & \multirow{2}{*}{$\begin{array}{l}\text { Predominantly indigenous Indian collection and } \\
\text { Mexican cultivars that paved the way for green } \\
\text { revolution }\end{array}$} & Kharchia Local, Karchia65, IC212184 & Kharchia \\
\hline & & $\begin{array}{l}\text { Sonalika, SONORA64, Safed Lerma, UP262, } \\
\text { Sel111, HW2001 }\end{array}$ & Sonalika \\
\hline 4 & $\begin{array}{l}\text { Predominantly genetic stocks for disease (brown/black/ } \\
\text { yellow rusts, leaf blight) resistance }\end{array}$ & FLW3, FLW5, FLW11 & Multiple rust resistance \\
\hline \multirow{4}{*}{5} & \multirow{4}{*}{$\begin{array}{l}\text { Predominantly multi-parent derived recent genotypes } \\
\text { having PASTOR and MILAN in their pedigree }\end{array}$} & DPW621-50, DBW88, HD3059 & Common pedigree \\
\hline & & HD3016, WH1132, WH1138 & Common pedigree \\
\hline & & $\begin{array}{l}\text { DBW98, DBW129, HPW400, WH1164, } \\
\text { WH1156, HUW661, HPW349 }\end{array}$ & PASTOR \\
\hline & & $\begin{array}{l}\text { HUW675, HUW666, HPW373, HD3133, } \\
\text { MP1201, HS507, HS542, WH1105 }\end{array}$ & Milan \\
\hline 6 & $\begin{array}{l}\text { Predominantly derivatives of PBW343 (also referred } \\
\text { as 'Veery' lines) }\end{array}$ & $\begin{array}{l}\text { PBW343, PBW596, PBW502, VL907, PBW723, } \\
\text { PBW693, PBW722, KB2012-03, FLW30, FLW29 }\end{array}$ & PBW343 \\
\hline
\end{tabular}

Table 2. Predominant progenitors identified in different groups of wheat genotypes.

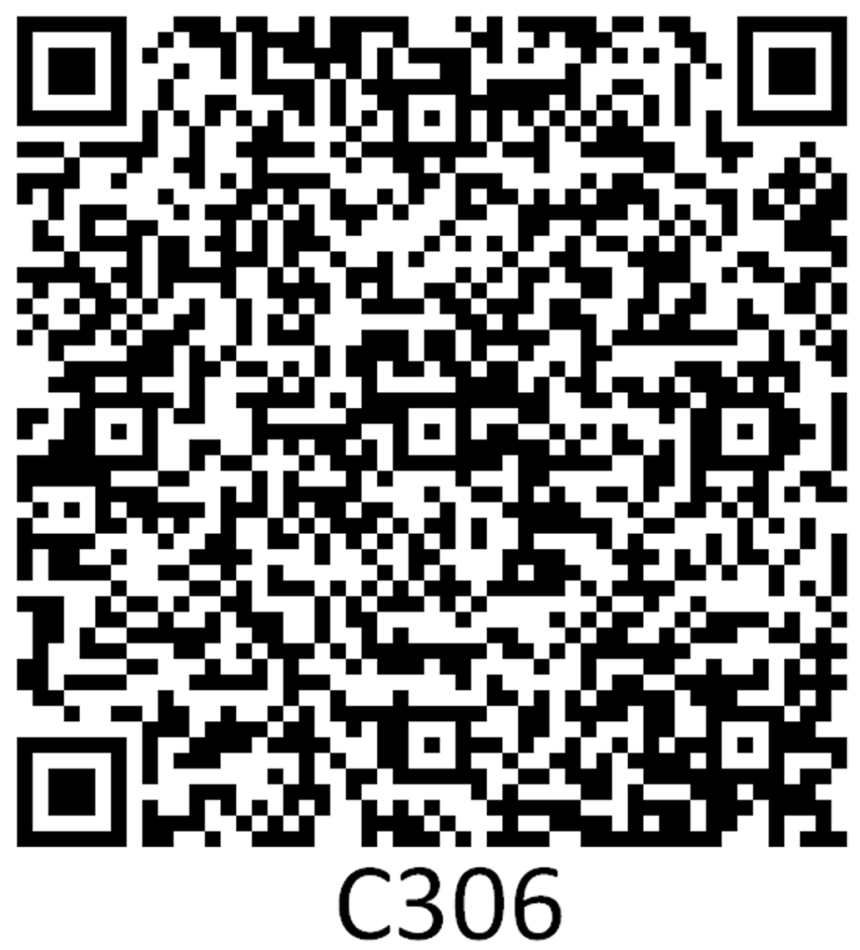

Figure 4. Barcode (2D) of a representative variety of wheat used in the present study.

phenotype differences ${ }^{34}$, for example, a non-sense mutation SNP in anthocyanidin synthase gene associated with phenotype uniqueness like yellow pigmentation in raspberry variety has been successfully used ${ }^{35}$. Similar functional SNP associated with DUS feature in barley is also reported ${ }^{36}$.

Our approach can be a model for availability of allelic data in public domain obviating the need of genotyping data generation by multiple users/countries thus would be more logical and economic. In the era of digital communication using hand held communication devices, the present developed mobile app can further popularize this approach of server having huge data of SNP array and varietal signature for remote accessibility and rapid use. Such model user friendly tool can be popular for other crops also as it does not require computational expertise at user end. In era of globalization and best use of germplasm across country, variety identification system can play role in management of germplasm and issues of access benefit sharing (ABS). 


\section{Conclusion}

A model web server has been developed successfully for crop variety identification using throughput SNP data of $>350$ wheat varieties by $35 \mathrm{~K} \mathrm{SNP}$ chip. VISTa is world's first web server for variety identification of any crop using SNP data. In order to make cost effective and rapid genotyping, SNP varietal signature has been successfully made by reduction of SNP up to 54 without compromising identification of $>350$ varieties. These 54 SNPs based phylogenetic tree confirms six major trait based clusters of Indian wheat varieties along with their pedigree. This tool can also generate QR code to facilitate bar-coding of each variety required for germplasm management. This approach can overcome on limitation of phenotypic data based variety identification by supplementation of molecular data. This server can not only be a model for other crops but can also be used for DUS varietal testing, dispute resolution of sovereignty and $\mathrm{ABS}$ issues which is not very uncommon in germplasm movement and improvement in the endevour of wheat productivity and management.

\section{Data Availability}

http://webtom.cabgrid.res.in/vista.

\section{References}

1. Food and Agriculture Organization of the United Nations. FAOSTAT. Available at www.fao.org/faostat/en/. Accessed August 16, 2016 (2014).

2. Jarvis, D. I. et al. A global perspective of the richness and evenness of traditional crop-variety diversity maintained by farming communities. Proceedings of the National Academy of Sciences 105, 5326-5331, https://doi.org/10.1073/pnas.0800607105 (2008).

3. Korir, N. K. et al. Plant variety and cultivar identification: advances and prospects. Critical reviews in biotechnology 33, 111-125 (2013).

4. Esquinas-Alcázar, J. Protecting crop genetic diversity for food security: political, ethical and technical challenges. Nature Reviews Genetics 6, 946 (2005).

5. Rameshan, P. (Ed.). WTO, India, and Emerging Areas of Trade: Challenges and Strategies. Excel Books India, 3-29 (2008).

6. Jones, H., Jarman, R. J., Austin, L., White, J. \& Cooke, R. J. The management of variety reference collections in distinctness, uniformity and stability testing of wheat. Euphytica 132, 175-184 (2003).

7. Rasheed, A. et al. Crop breeding chips and genotyping platforms: progress, challenges, and perspectives. Molecular plant 10, 1047-1064 (2017).

8. Saghai-Maroof, M. A., Soliman, K. M., Jorgensen, R. A., Allard, R. W. \& Ribosomal, D. N. A. spacer-length polymorphisms in barley: Mendelian inheritance, chromosomal location, and population dynamics. Proceedings of the National Academy of Sciences 81, 8014-8018 (1984).

9. Doyle, J. J. \& Doyle, J. L. Isolation of plant DNA from fresh tissue. Focus 12, 13-15 (1990).

10. Liu, K. \& Muse, S. V. PowerMarker: an integrated analysis environment for genetic marker analysis. Bioinformatics 21, 2128-2129 (2005).

11. Fujii, H. et al. Minimal marker: an algorithm and computer program for the identification of minimal sets of discriminating DNA markers for efficient variety identification. Journal of bioinformatics and computational biology 11, 1250022 (2013).

12. Henning, J. A., Coggins, J. \& Peterson, M. Simple SNP-based minimal marker genotyping for Humulus lupulus L. identification and variety validation. BMC research notes 8, 542 (2015).

13. Cabezas, J. A. et al. A 48 SNP set for grapevine cultivar identification. BMC plant biology 11, 153 (2011).

14. Lu, F., Glaubitz, J., Harriman, J., Casstevens, T. \& Elshire, R. TASSEL 3.0 Universal Network Enabled Analysis Kit (UNEAK) pipeline documentation. White Paper 1-12 (2012).

15. van Berloo, R. GGT 2.0: versatile software for visualization and analysis of genetic data. Journal of Heredity 99, 232-236 (2008).

16. Tamura, K., Dudley, J., Nei, M. \& Kumar, S. MEGA4: molecular evolutionary genetics analysis (MEGA) software version 4.0. Molecular biology and evolution 24, 1596-1599 (2007).

17. Gao, L., Jia, J. \& Kong, X. A SNP-based molecular barcode for characterization of common wheat. PloS one 11, e0150947 (2016).

18. Wang, S. et al. Characterization of polyploid wheat genomic diversity using a high-density 90000 single nucleotide polymorphism array. Plant biotechnology journal 12, 787-796 (2014).

19. Daniels, R. et al. A general SNP-based molecular barcode for Plasmodium falciparum identification and tracking. Malaria journal 7,223 (2008).

20. Coll, F. et al. A robust SNP barcode for typing Mycobacterium tuberculosis complex strains. Nature communications 5, 4812 (2014).

21. Rodrigues, D. H., de Alcântara Neto, F. \& Schuster, I. Identification of essentially derived soybean cultivars using microsatellite markers. Crop Breeding and Applied Technology 8, 74 (2008).

22. Jung, H. J. et al. A System for Distinguishing Octoploid Strawberry Cultivars Using High-Throughput SNP Genotyping. Tropical Plant Biology 10, 68-76 (2017).

23. Müller, T. et al. Unlocking the diversity of genebanks: whole-genome marker analysis of Swiss bread wheat and spelt. Theoretical and Applied Genetics 131, 407-416 (2018).

24. Chen L. Potato Variety Identification with a Panel of SNPMarkers, Wageningen University (Unpublished M.Sc. thesis) (2016).

25. Liu, Z. et al. Assessing the numbers of SNPs needed to establish molecular IDs and characterize the genetic diversity of soybean cultivars derived from Tokachi nagaha. The Crop. Journal 5, 326-336 (2017).

26. Kuang, M. et al. Development of a core set of SNP markers for the identification of upland cotton cultivars in China. Journal of Integrative Agriculture 15, 954-962 (2016).

27. Jones, L., Wall, S., Nelson, B. \& Smith S. Varietal identification in maize: are sixteen snp markers sufficient?. Working group on biochemical and molecular techniques and DNA profiling in particular, Twelfth Session. Ottawa, Canada. International Union For The Protection Of New Varieties Of Plants, GENEVA (2013).

28. Allen, A. M. et al. Characterization of a Wheat Breeders' Array suitable for high-throughput SNP genotyping of global accessions of hexaploid bread wheat (Triticum aestivum). Plant biotechnology journal 15, 390-401 (2017).

29. Galimberti, A. et al. DNA barcoding for minor crops and food traceability. Advances in Agriculture 2014 (2014).

30. King, R. et al. Mutation scanning in wheat by exon capture and next-generation sequencing. PLoS One 10, e0137549 (2015).

31. Ramirez-Gonzalez, R. H., Uauy, C. \& Caccamo, M. PolyMarker: a fast polyploid primer design pipeline. Bioinformatics 31, 2038-2039 (2015).

32. Guo, H. et al. Development of a high-efficient mutation resource with phenotypic variation in hexaploid winter wheat and identification of novel alleles in the TaAGP. L-B1 gene. Frontiers in plant science 8, 1404 (2017).

33. Mo, Y. et al. Mapping causal mutations by exome sequencing in a wheat TILLING population: a tall mutant case study. Molecular Genetics and Genomics 293, 463-477 (2018).

34. Huq, M. A. et al. Identification of functional SNPs in genes and their effects on plant phenotypes. Journal of Plant Biotechnology 43, 1-11 (2016). 
35. Rafique, M. Z. et al. Nonsense mutation inside anthocyanidin synthase gene controls pigmentation in yellow raspberry (Rubus idaeus L.). Frontiers in plant science 7, 1892 (2016).

36. Jones, H. \& Mackay, I. Implications of using genomic prediction within a high-density SNP dataset to predict DUS traits in barley. Theoretical and applied genetics 128, 2461-2470 (2015).

\section{Acknowledgements}

Authors are thankful to Indian Council of Agricultural Research, Ministry of Agriculture and Farmers' Welfare, Govt. of India for Advanced Super Computing Hub for Omics Knowledge in Agriculture (ASHOKA) facility at ICAR-IASRI, New Delhi, India created under National Agricultural Innovation Project, funded by World Bank. This work was supported by the Indian Council of Agricultural Research, Ministry of Agriculture and Farmer's Welfare, Government of India by providing financial assistance in the form of CABin grant (F. No. Agril. Edn.41/2013-A\&P).

\section{Author Contributions}

R.T. and Di.K. conceived the theme of the study. R.S., M.A.I. and C.M. drafted the manuscript. M.A.I., S.J., N.K. and U.B.A. did the computational analysis and developed database. A.G., R.T., R.S., N.R. and De.K. did the phenotyping. R.S., De.K., N.R., S.P., P.S. and S.S. contributed in lab work. V.T., A.R., G.S., R.T., Di.K. and S.J. edited the manuscript. All co-authors read and approved the final manuscript.

\section{Additional Information}

Supplementary information accompanies this paper at https://doi.org/10.1038/s41598-019-41204-2.

Competing Interests: The authors declare no competing interests.

Publisher's note: Springer Nature remains neutral with regard to jurisdictional claims in published maps and institutional affiliations.

(c) (i) Open Access This article is licensed under a Creative Commons Attribution 4.0 International License, which permits use, sharing, adaptation, distribution and reproduction in any medium or format, as long as you give appropriate credit to the original author(s) and the source, provide a link to the Creative Commons license, and indicate if changes were made. The images or other third party material in this article are included in the article's Creative Commons license, unless indicated otherwise in a credit line to the material. If material is not included in the article's Creative Commons license and your intended use is not permitted by statutory regulation or exceeds the permitted use, you will need to obtain permission directly from the copyright holder. To view a copy of this license, visit http://creativecommons.org/licenses/by/4.0/.

(c) The Author(s) 2019 